\title{
Study of Personality Characteristics of Children with High and Low Challenging Behavior Patterns
}

\author{
Anita Gautam ${ }^{1}$, Anjana Mukhopadhyay ${ }^{2}$
}

\section{ABSTRACT}

Challenging behaviour is a broadly used term which generally refers to behaviour that is seen as abnormal within the context of person's culture. It can denote a range of behaviours such as self injury, aggression, sexualised behaviour and destruction of property and often refers to more than one of these behaviours that co-exist. When children show persistent social, emotional and or behavioural difficulties, they need to be identified early, so that the abusive temperament may not convert into challenging personality traits. Growth period of late childhood is the period when they learn to regulate their emotions, cope with sensory input, express their desires, and develop relationships with others. Immature identity and self structure often pose vulnerability in their behaviour pattern and the child develops emotional outburst like crying, throwing, biting and deny social rules. Social agents like family, school and other systems train them to navigate the situation. However behaviour of this age group of children when appear worrisome often defined as challenging. Failing of address the challenging behaviours at this stage may create personality problem. Research outcomes indicate that services that address challenging behaviours may receive the health approach towards personality development. The broad objective of the study is to understand personality characteristics between children with high challenging behaviour and low challenging behaviour group. The sample of 150 parents and guardians are included for identifying the challenging behaviour patterns in children by administrating Coolidge Personality and Neuropsychological Inventory for Children. Out of this 30 children affected with challenging behaviour (high challenging behaviour $\mathrm{N}=15$ \& low challenging behaviour $\mathrm{N}=15$ ) were selected for the study. Children Personality Questionnaire by Kapoor \& Rao was administered on both the groups. To study how much they differ in terms of their personality characteristics out of 14 factors, groups differed on 5 factors A,D,E,I and Q4 differed on 5 factors A,D,E,I and Q4 of personality characteristics. High challenging behaviour children reported high warm hearted (A), excitable (D), dominant (E), tender minded (I) and with high ergic tension (Q4) $(\mathrm{t}<0.05 /<0.01)$.

Keywords: Challenging behavior, Personality characteristics

\footnotetext{
${ }^{1}$ Research Scholar, Department of Psychology, Banaras Hindu University, Varanasi, India

${ }^{2}$ Professor, Department of Psychology, MMV, Banaras Hindu University, Varanasi, India

*Responding Author
}

Received: January 21, 2017; Revision Received: March 6, 2017; Accepted: March 10, 2017

(C) 2017 Gautam A, Mukhopadhyay A; licensee IJIP. This is an Open Access Research distributed under the terms of the Creative Commons Attribution License (www.creativecommons.org/licenses/by/2.0), which permits unrestricted use, distribution, and reproduction in any Medium, provided the original work is properly cited. 


\section{Study of Personality Characteristics of Children with High and Low Challenging Behavior Patterns}

Behaviours considered difficult or unmanageable by one professional, parent or pupil often are not classified as challenging by others. Challenging Behaviour' is an umbrella term representative of any behaviour that exposes an individual and those around them to risk. These behaviours can range from physical or verbal aggression to self-injurious acts or obsession conduct, and are commonly found in individuals with intellectual disability (Emerson \& Enfield, 2011).

Challenging behavior is any behavior that interferes with a child‘s cognitive, social, or emotional development. As such challenging behavior may be harmful to a child, his peers, or adults and puts a child at high risk for later social problems or school failure (Klass, Guskin, \& Thomas, 1995; Ritchie and Pohl, 1995). Challenging behaviour in the form of aggressive and anti-social behaviours is consistently reported as a persistent and widespread challenge within the school environment, presenting daily problems for both parents and teachers. These behaviours are of particular interest within education policy and practice due to their robust and explicit association with long term adverse problems. For instance, persistent aggressive behaviour within the early years has been identified as a primary, contributory risk factor for substance abuse, delinquency and truancy, gang membership and an increased risk of mental health problems throughout adulthood (Foxcroft \& Tsertsvadze, 2013). Furthermore, longitudinal studies have identified that increased aggression and anti-social behaviour throughout childhood establishes sequences of aggressive behaviour into adulthood, (Romano et al., 2005).

Within the school environment, expression of challenging behaviour is problematic due to the direct interference with learning, development and eventual success of the child (Klass, Guskin \& Thomas, 1995; Ritchie \& Pohl, 1995). Without sensitive and effective implementation of interventions, challenging school behaviour becomes a barrier to learning, and put the child at an academic disadvantage. The longer a child engages with anti-social behaviour as a means of expression, the greater the consequences become and the more difficult it is to modify the aggressive behavioural response; it is therefore essential to intervene and prevent a child from entering the inevitable cycle of poor life quality at the earliest opportunity (Slaby et al., 1995). There are two broad classes of emotional and behavior disorders:

\section{Externalizing disorders}

In this group are students who act out or direct their feelings outwards. The group includes oppositional defiant disorder, where children behave in negative, hostile ways, losing their temper, arguing, defying, and refusing to comply; and conduct disorders, where students persistently break rules, bully others, and act aggressively (U.S. Department of Health and Human Services, 2003). 


\section{Study of Personality Characteristics of Children with High and Low Challenging Behavior Patterns}

\section{Internalizing disorders}

In this group are students who withdraw or turn their feelings inward. Included here are eating disorders; anxiety disorders, such as obsessive compulsive disorder, posttraumatic stress disorder, and phobias; and mood disorders, such as depression, bipolar illness, and schizophrenia (U.S. Department of Health and Human Services, 2003).

Pathak et. al. (2008) reported a prevalence of behavioral and emotional problems in 12-18 year age group of adolescents to be $30 \%$ among girls with maximum of internalizing symptoms and exceeding boys in all age groups.

Hallahan and Kaufman (2005) proposed a third classification of behavioral disorders. They found some children to be immature or underdeveloped in their social and behavioral skills. Both or either externalizing and internalizing forms of behaviour are picked up by such children. Students with emotional and behavior problems often have other co-morbid disorders such as ADHD, learning disability, or difficulty with language (Benner, Nelson \& Epstein, 2002). As a result, they have great trouble in the academic practices and problems with social skills and friendships. Such problems can lead to scholastic troubles, because their social skills, emotional control, and language development are often not found at par with their age: appropriate developmental level. Many students with challenging behavior are unprepared for the most basic tasks of early schooling. Symptoms enlisted like Hyperactivity, inattentiveness, and inability to concentrate also influence their learning ability.

Personality traits are defined as the relatively enduring patterns of thought, feeling and behaviours that distinguish individuals from one another. The individual recognizes itself as if encounters circumstances and experiences in life, perceptible patterns gradually ensure the uniqueness and differentiation. Considering that personality is a dynamic process and it is marked by some predispositions, that is, the personality traits. Studies have shown personality traits continue to change in adulthood and often in to old age, and that these changes may be quite substantial and consequential.

Considerable evidence suggests that youth who engage in early risk taking, such as drug use and aggressive behavior, exhibit higher levels of impulsive behavior in the early age (Caspi \& Silva, 1995; Caspi, Henry, McGee, Moffitt, \& Silva, 1995; Caspi, Moffitt, Newman, \& Silva, 1996; Masse \& Tremblay, 1997; Raine, Reynolds, Venables, Mednick, \& Farrington, 1998). Indeed, the entire spectrum of externalizing behavior appears to be related to a core set of impulsive traits (Kreuger et al., 2002) that is evident in early in development at phase (McGue, Iacono, \& Kreuger, 2006). This evidence is again supportive of the idea that a good deal of the problematic behavior observed in adolescents is clustered in a small percentage of youth. 
Study of Personality Characteristics of Children with High and Low Challenging Behavior Patterns

\section{Major Objectives}

1. To screen out children with high and low challenging behavioral symptoms.

2. To determine personality factors in the selected groups of children.

\section{Hypotheses of the Study}

1. Children with high challenging behaviours would score high on traits of dynamic disposition namely A, D, E, F and general intelligence namely B, H, I, N, and Q4 than their comparative control counterparts.

2. Children with high challenging behaviours would score low on traits of emotional and ethical component C, G, J, O and Q3 than their comparative control counterpart.

\section{METHODOLOGY}

\section{Sample}

The samples of the present study have been selected from the Tulsi Vidya nikaten, Sant JPS Sankat mochan, Mahamana Madhan Mohan Malviya School Sankat Mochan, Central Hindu Boys school and Kendriya Vidyalaya BHU of Varanasi. A total population of 150 school children of an age range of 9-14 year were included A total sample of 30 children of 15 high and 15 low challenging behaviour (both boys and girls) were finally screened and included on the basis of CPNI questionnaire results. Mean and SD on all the subscales of CPNI were calculated, M+1SD decided the cut off score to find out high challenging behavior and M-1SD decided the cut off score for low challenging behavior of school children. Selected children of both of the groups who volunteered for the study. The screenings of challenging behaviours were done by the parents and with the help of class teachers of the students in classroom atmosphere. The selected school students $(\mathrm{N}=30)$ were then assessed on the basis of CPQ to find out their personality traits.

\section{Tools}

The following psychological scales have been selected to achieve the above mentioned objectives,

1. Coolidge Personality and Neuropsychological Inventory for Children (CPNI) (Coolidge, 1992) The CPNI is a 200 item pencil and paper battery of tests designed to be filled out by parent or guardian of children. CPNI is designed to assess children from age 5 to 17 years old. The scale is divided into eight broader categories and each scale has different subscales. Present investigation has taken the neuropsychological scale consisting of general neuropsychological subscale, neuro-somatic subscale, learning problem subscale, language problem subscale, memory difficulty subscale, perceptual motor dysfunction subscale, executive dysfunction subscale, sub-cortical subscale, inattention subscale, hyperactivity subscale, impulsive subscale, delayed maturation subscale and emotional change subscale. The reliability correlation coefficient value of which is ranged from 0.46 to 0.86 . 
2. Indian Adaptation of Children Personality Questionnaire (CPQ) (Kapoor \& Rao, 1972). Children personality questionnaire is available in two forms, i.e. form B1 and form B2 containing 70 items in each form. The CPQ measures a set of fourteen personality factor dimensions of personality traits, namely, emotional stability, self concept level, excitability and apprehension. Scores for extraversion, anxiety and other broad trait patterns are also obtained as combination of the primary scales. The reliability correlation coefficient value of the scale is ranged from 0.42 to 0.84 and validity of the scale is from 0.20 to 0.90 .

\section{RESULT AND DISCUSSION}

The mean and standard deviations of the personality score of the two groups (high and low challenging behaviour) were computed. The significance of difference between the scores of the two groups were analysed by computing t- test.

Table1: Means SDs and t-values of high challenging behaviour and low challenging behaviour group on fourteen personality factors of children personality questionnaire scores.

\begin{tabular}{|l|l|l|l|l|l|l|}
\hline \multicolumn{3}{|l|}{ High challenging behavior (N=15) } & \multicolumn{4}{l|}{ Low challenging behavior (N=15) } \\
\hline Factors & Mean & SD & Mean & SD & t- value & Level of significance \\
\hline A & 5.07 & 1.22 & 3.93 & 1.66 & 2.12 & $0.043^{* *}$ \\
\hline B & 3.13 & 1.24 & 3.00 & 1.55 & 2.59 & 0.798 \\
\hline C & 5.00 & 1.36 & 4.53 & 1.36 & .940 & 0.355 \\
\hline D & 6.07 & 1.16 & 4.53 & 1.35 & 3.32 & $0.002^{* *}$ \\
\hline E & 7.20 & 1.56 & 4.33 & 1.79 & 4.65 & $0.000^{* *}$ \\
\hline F & 4.80 & 1.32 & 4.40 & 1.40 & .804 & 0.428 \\
\hline G & 5.00 & 1.73 & 4.47 & 2.13 & .752 & 0.459 \\
\hline H & 5.00 & 1.51 & 4.80 & 1.97 & .312 & 0.757 \\
\hline I & 5.67 & 1.83 & 4.20 & 1.61 & 2.32 & $0.028^{*}$ \\
\hline J & 5.60 & 1.84 & 4.67 & 1.71 & 1.43 & 0.163 \\
\hline N & 4.60 & 2.16 & 4.13 & 1.80 & .641 & 0.527 \\
\hline O & 5.27 & 2.31 & 7.27 & 13.31 & .573 & 0.571 \\
\hline Q3 & 4.67 & 1.34 & 4.00 & 2.03 & 1.05 & 0.299 \\
\hline Q4 & 5.53 & 1.35 & 3.33 & 1.71 & 3.89 & $0.001 * *$ \\
\hline
\end{tabular}

$* * p<0.01, * p<0.05$

Table 1 present the means, standard deviation and t- values for all the 14 bipolar personality factors measured through children personality questionnaire of high and low challenging behavior groups. Out of 14 factors the t- values recorded for the traits of dynamic disposition namely warm-hearted (Factor A) excitable (D), assertive (E) and enthusiastic (F) are higher mean scores than there comparative low challenging counterparts. High challenging behavior group have significantly ( $<<0.01$ ) higher on factors $A, D$ and $E$ while the value is not statistically significant for factor F. Thus it means that children with high challenging behavior 


\section{Study of Personality Characteristics of Children with High and Low Challenging Behavior Patterns}

are easy going, excitable, demanding and more aggressive than low challenging behavior group. As per hypothesis 1 factors on traits of general intelligence namely factor B, H, I, N and Q4. Two factors out of five have reported significant $t-$ value. Factor I i.e. tender minded $(\mathrm{p}<0.05)$ and factor $\mathrm{Q} 4$ i.e. tense $(\mathrm{p}<0.01)$ have established as hypothesized for high challenging behavior group. Mean differences obtained on factor $\mathrm{B}$ i.e. bright, factor $\mathrm{H}$ i.e. venturesome and factor $\mathrm{N}$ i.e. shrewd however have not been attained significant t- values. Thus the hypotheses 1 is partially accepted. The t-value of factor C, G and J described low emotional stability, disregarding rules and vigorous however do not differentiate high challenging behavior and low challenging behavior on traits of emotional components. The factor $\mathrm{O}$ that is untroubled adequacy has reported low mean score as hypothesized through $t$ has not been reported significant. Factor Q3 which measured and low integration based on traits of ethical component has reported higher mean score among high challenging behavior children against hypotheses than low challenging behavior group. Thus the hypothesis 2 of low scores on traits of emotional and ethical component is rejected.

Personality is frequently used in our present day terminology to refer man's behavior and characteristics. There are significant differences in the manifestation of characteristics, traits or factors that comprises the whole personality pattern which can be described in terms of the functioning of the various traits that reflects personality. In order to adapt to the present scenario and keep pace with the competitive world children are required to have an emotional charge for which they are not always ready to bear and which leads to stress.

Challenging behaviours present serious and deleterious implications for all aspects of young children's developments. A systematic, evidence-based approach is required to be promoted and adopted by teachers, care givers and parents. The initiative taken by the adults may be systematically handled on the basis of the personality factors of their words. The target develop positive self concept, confidence and a sense of safety that help reduce challenging behavior. Thus a conclusion may be drawn that identification of challenging behavior symptoms during childhood or adolescence may check and modify it in to right direction towards positivity during the turning points of 11 to 13 years when the foundation of personality instability is laid.

\section{Acknowledgments}

The author appreciates all those who participated in the study and helped to facilitate the research process.

Conflict of Interests: The author declared no conflict of interests.

\section{REFERENCES}

Benner, G. J., Nelson, J. R., \& Epstein, M. H. (2002). Language skills of children with EBD: A literature review. Journal of Emotional and Behavioral Disorders, 10, 43-59. 


\section{Study of Personality Characteristics of Children with High and Low Challenging Behavior Patterns}

Caspi, A. Henry, B., McGree, R.O., Moffitt, T.E., \& Silva P.A. (1995). Temperamental origins of child and adolescent behavior problem: From age three to age fifteen. Child Development, 66, 55-68.

Caspi, A., Moffitt, T.E., Newman, D.L., \& Silva, P.A. (1996). Behavioral observations at age 3 years predict adult psychiatric disorders. Archives of General Psychiatry, 53, 1033-1039.

Caspi, A., Silva, P. (1995). Temperamental qualities at age three predict personality traits in young adulthood: Longitudinal evidence from a birth cohort. Child Development, 66, 486-498.

Coolidge, F. L. (1992). The Coolidge personality and neuropsychological inventory for children. Colorado Springs. University Of Colorado.

Emerson, E. and Enfield, S. L. (2011) Challenging Behaviour. 3rd Ed. Cambridge University Press: England.

Foxcroft, D. R., \& Tsertsvadze, A. (2013) Universal alcohol misuse prevention programmes for children and adolescents: Cochrane systematic reviews. Perspectives in Public Health, 3, 132-136.

Hallahan, D. \& Kaufman, J. (2005). Exceptional Learners: Introduction to Special Education. Ca.,USA: Allyn \& Bacon.

Kapoor, S.D. \& Rao, S. (1972). Indian adaptation of children of personality questionnaire. The Psycho- Center.

Klass, C. S., Guskin, K. A., \& Thomas, M. (1995). The early childhood program: Promoting children's development through and within relationships. Zero to Three, 16, 9-17.

Kreuger, R.F., Hicks B.M., Patrick, C.J., Carlson, S.R., Lacono, W.G., and McGue, M. (2002). Etiological connections among substance dependence, antisocial behavior and Personality: Modeling the externalizing apectrum. Journals of Abnormal Psychology, 111, 411-424.

Masse, L.C., \& Tremblay, R.E. (1997). Behavior of boys in Kindergarden and the onset of substance use during adolescence. Archives of General Psychiatry, 54, 62-68.

McGue, M., Lacono, W.G., \& Kreuger, R.F. (2006). The association of early adolescent problem behavior and adult psychopathology: A multivariate behavioral genetic perspective. Behavior Genetics, 36, 591-602.

Pathak, R., Sharma, RC., Parvan, UC., Gupta, B.P., Ojha, R.K. \& Goel N.K. (2008). Behavioral and emotional problems in school going adolescents. Australasian Medical Journal, 1, 15-21

Raine, A., Reynolds, C., Venables, P.H., Mednick,S.A. and Farrington, D.F. (1998). Fearlessness, stimulation- seeking, and large body size at age 3 years as early predispositions to childhood aggression at age 11 years. Archives of General Psychiatry,55,745-751.

Ritchie, J., \& Pohl, C. (1995). Rules of thumb workshop. The Early Childhood Educator, 10, 11-12.

Romano, E., Tremblay, R. E., Boulerice, B. and Swisher, R., (2005) Multilevel correlates of childhood physical aggression and pro-social behaviour. Journal of abnormal psychology, 33, 565-578. 
Slaby, R., Roedell, W., Arezzo, D. and Hendrix, K. (1995). Early violence prevention: tools for teachers of young children. National Association for the Education of Young Children. Washington, DC.

U.S. Department of Health and Human Services. (2003). Children's mental health facts: Children and adolescents with mental, emotional, and behavioral disorders. Washington, DC: SAMHSA‘s Mental Health Information Canter. www.mentalhealth.org/publications/allpubs/CA-0006/default.asp.

How to cite this article: Gautam A, Mukhopadhyay A (2017), Study of Personality Characteristics of Children with High and Low Challenging Behavior Patterns, International Journal of Indian Psychology, Volume 4, Issue 2, No. 93, ISSN:2348-5396 (e), ISSN:2349-3429 (p), DIP:18.01.129/20170402, ISBN:978-1-365-78193-3 